\title{
Ferroelectricity in glycine picrate: An astonishing observation in a centrosymmetric crystal
}

\author{
M. Shakir, ${ }^{1}$ B. K. Singh, ${ }^{2}$ B. Kumar, ${ }^{2}$ and G. Bhagavannarayana ${ }^{1, a)}$ \\ ${ }^{1}$ Materials Characterization Division, National Physical Laboratory, New Delhi 110012, \\ India and Council of Scientific and Industrial Research, New Delhi 110012, India \\ ${ }^{2}$ Department of Physics and Astrophysics, Crystal Lab, University of Delhi, Delhi 110007, India
}

(Received 23 October 2009; accepted 24 November 2009; published online 22 December 2009)

\begin{abstract}
Remarkable ferroelectric property has been observed in the glycine picrate single crystal though it crystallizes in centrosymmetric structure. An anomaly at $105{ }^{\circ} \mathrm{C}$ was observed in dielectric and ac conductivity measurements. The activation energies for conduction $\left(E_{\mathrm{a}}\right)$ below and above this temperature are found to be 0.31 and $0.53 \mathrm{eV}$, respectively. The remanant polarization $\left(P_{\mathrm{r}}\right)$ and coercive field $\left(E_{\mathrm{c}}\right)$ at room temperature were found to be $0.64 \mu \mathrm{C} / \mathrm{cm}^{2}$ and $6.22 \mathrm{kV} / \mathrm{cm}$, respectively. However, a remarkable increase in these values was observed above $105^{\circ} \mathrm{C}$. A significantly high $d_{33}$ (piezoelectric charge coefficient) in the order of $18 \mathrm{pC} / \mathrm{N}$ was observed. (C) 2009 American Institute of Physics. [doi:10.1063/1.3275714]
\end{abstract}

Organic materials find vast applications in the field of semiconductors, ${ }^{1}$ superconductors, ${ }^{2}$ and photonic devices. ${ }^{3,4}$ Due to the presence of active $\pi$ bonds in organic compounds, they are found to exhibit high nonlinear optical (NLO) response than that of inorganic counterparts. Picric acid is one of the organic compounds having tendency to form the stable picrate compounds with various organic molecules. ${ }^{5}$ Investigations of various amino acid picrates have attracted the attention of researchers in the recent past. ${ }^{6,7}$ Glycine picrate (GP) belongs to one of the amino acid picrate group. It belongs to monoclinic crystal system having lattice parameters $a=14.968, b=6.722$, and $c=15.165 \AA$ and space group $P 2_{1} / a{ }^{8,9}$ Being a centrosymmetric structure, one cannot predict NLO property. However, recent investigation has confirmed a remarkable NLO behavior in this material. ${ }^{10}$ This finding brings this material to the class of exceptions which includes NLO material having centrosymmetric structure. ${ }^{11,12}$ Further, noncentrosymmetry is also the basic requirement for the material to exhibit ferroelectricity. A ferroelectric material finds various applications in nonvolatile memory and hence most of the researchers are attracted toward finding a material with fairly good ferroelectric and piezoelectric properties. Further, in the recent scenario, the trend is toward the development of organic ferroelectric material. ${ }^{13,14}$

In the present work, we motivated our self with a question, "if the centrosymmetric GP single crystal can exhibit NLO property then, is it possible for the same to exhibit ferroelectric behavior as well?" To find the answer, GP single crystals were grown by slow evaporation solution technique (SEST) and the ferroelectric response was investigated. Surprisingly, the existence of ferroelectricity in GP single crystal was found. Further, piezoelectric and dielectric properties of the crystal were carried out and the results were analyzed and discussed.

Single crystals of GP were grown using conventional solution growth method at $47{ }^{\circ} \mathrm{C}$. About $25 \mathrm{~g}$ of high grade glycine and picric acid were used as starting materials in the

\footnotetext{
a) Author to whom correspondence should be addressed. Electronic mail: bhagavan@mail.nplindia.ernet.in.
}

1:1 molar ratio. The details of the growth process are reported recently. ${ }^{10}$ The grown single crystals were finely grinded and subjected to powder XRD in the range $10^{\circ}$ to $60^{\circ}$ of $2 \theta$ with a step angle of $0.01^{\circ}$ with step time $0.5 \mathrm{~s}$ using PW3710 based Philips powder x-ray diffractometer $\left(\mathrm{Cu} \mathrm{K}{ }_{\alpha}\right.$ radiation). The obtained lattice parameters and the evaluation of crystalline perfection using high-resolution $\mathrm{x}$-ray diffractometry are reported very recently. ${ }^{10} \mathrm{~A}$ sample was prepared by electroding [using a high grade silver paste on both ends of (001) facet] and drying at $60{ }^{\circ} \mathrm{C}$ for various measurements. The electric hysteresis loops were measured with a computer-controlled modified Sawyer-Tower circuit. A home-made heating chamber with Pt 100 type thermocouple was used to heat and monitor the temperature. During measurements, the sample was submerged in insulating oil. Crystals were poled by applying a field of $15 \mathrm{kV} / \mathrm{cm}$ at $40{ }^{\circ} \mathrm{C}$ for $10 \mathrm{~min}$. The piezoelectric charge coefficient $d_{33}$ $(\mathrm{pC} / \mathrm{N})$ was measured using piezometer (PM300, Piezotest). The temperature dependence of real and imaginary parts of dielectric constant, dielectric loss, and ac conductivity were measured with a $4284 \mathrm{~A}$ impedance analyzer at a fixed frequency $(1 \mathrm{kHz})$. During measurements, the temperature of the sample (kept in the heating chamber) was varied from room temperature to $160{ }^{\circ} \mathrm{C}$ with a constant heating rate of $3{ }^{\circ} \mathrm{C} / \mathrm{min}$. However, the rate was brought down to $1{ }^{\circ} \mathrm{C} / \mathrm{mm}$ in the temperature range $100-110^{\circ} \mathrm{C}$ due to the observed anomaly found at $105^{\circ} \mathrm{C}$.

The variation of real $\left(\varepsilon^{\prime}\right)$ and imaginary $\left(\varepsilon^{\prime \prime}\right)$ parts of dielectric constant of unpoled GP single crystal with temperature at $1 \mathrm{kHz}$ is shown in Fig. 1(a). The dielectric constant of the sample is found to be in the range of 45-75 in the temperature range 25 to $160{ }^{\circ} \mathrm{C}$. As seen in the figure, nearly constant values of $\varepsilon^{\prime}$ and $\varepsilon^{\prime \prime}$ are observed below $105{ }^{\circ} \mathrm{C}$ with a small kink at $\sim 105{ }^{\circ} \mathrm{C}$. The kink may be due to some ferroelectric to ferroelectric phase transition. Further, a sharp increase beyond $120{ }^{\circ} \mathrm{C}$ is observed till $160{ }^{\circ} \mathrm{C}$. It is to be mentioned here that the observed flatness and onset of declination in the values of $\varepsilon^{\prime}$ and $\varepsilon^{\prime \prime}$ near $160{ }^{\circ} \mathrm{C}$ may be due to the starting of the softening of the crystal beyond this temperature. So, the peak at $\sim 160{ }^{\circ} \mathrm{C}$ could not be judged as its Curie temperature $\left(T_{\mathrm{c}}\right)$, i.e., the transition/critical tempera- 

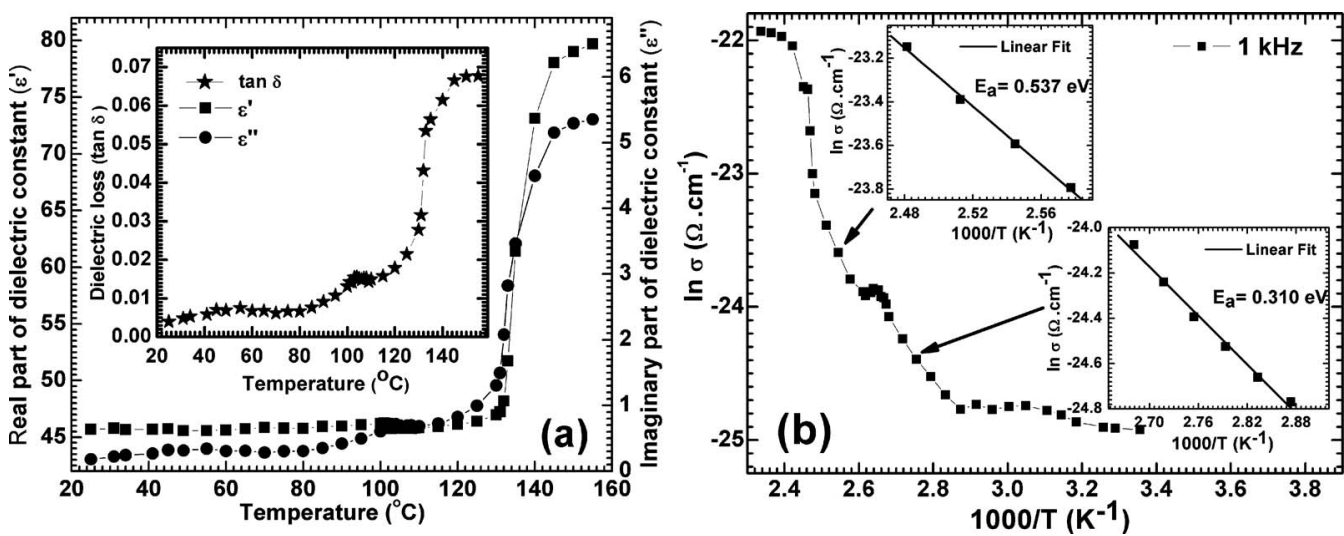

FIG. 1. The variation of (a) real and imaginary parts of dielectric constant and dielectric loss (inset figure) of unpoled GP single crystal with temperature at $1 \mathrm{kHz}$ and (b) $\ln \sigma$ vs inverse of temperature at $1 \mathrm{kHz}$. The inset in Fig. 1(b) shows the linear fitting (above and below 105 ${ }^{\circ} \mathrm{C}$ ) of Arrhenius equation for conductivity.

ture of ferroelectric to paraelectric phase transition. This result is also supported by the hysteresis behavior with temperature as described in the forthcoming paragraph. This suggests that the system do not show its Curie temperature up to $160^{\circ} \mathrm{C}$, beyond which it losses its stability. A similar behavior is observed for tan $\delta$ [inset of Fig. 1(a)].

Imaginary part of the dielectric constant can be related to ac conductivity $\sigma$ as $\sigma=\varepsilon_{0} \omega \varepsilon^{\prime \prime},{ }^{15}$ where $\varepsilon_{0}$ and $\omega$ are permittivity of free space and angular frequency, respectively. The variation of the ac conductivity (calculated from the imaginary part of dielectric constant data) with inverse of temperature is shown in Fig. 1(b). A smooth increase in the ac conductivity is observed till $160{ }^{\circ} \mathrm{C}$ with a discontinuity at $105^{\circ} \mathrm{C}$. This anomaly is attributed to the ferro-ferro second order phase transition. The ac conductivity is given by Arrhenius equation $\sigma=\sigma_{\mathrm{o}} \exp \left(-E_{\mathrm{a}} / k_{\mathrm{B}} T\right),{ }^{15}$ where ' $\sigma_{\mathrm{o}}$ is the pre-exponential factor, " $E_{\mathrm{a}}$ " is the activation energy for conduction, and " $k_{\mathrm{B}}$ " is the Boltzmann constant. A linear behavior below and above the anomaly $\left(\sim 105^{\circ} \mathrm{C}\right)$ is observed. The activation energy for conduction $\left(E_{\mathrm{a}}\right)$ above and below the anomaly $\left(105^{\circ} \mathrm{C}\right)$ is calculated for $1 \mathrm{kHz}$ by using the Arrhenius equation $\sigma=\sigma_{\mathrm{o}} \exp \left(-E_{\mathrm{a}} / k_{\mathrm{B}} T\right)$ and is found to be 0.53 and $0.31 \mathrm{eV}$, respectively [inset of Fig. 1(b)].
The GP single crystals were subjected to piezoelectric characterization. For this, the poling conditions were optimized by observing the response of the crystals under different applied electric fields, temperature, and duration of poling. It is observed that the crystal can withstand high electric field up to $23 \mathrm{kV} / \mathrm{cm}$, beyond which cracks were observed to develop in the crystals. Hence a moderate electric field upto $15 \mathrm{kV} / \mathrm{cm}$ at a temperature of $40{ }^{\circ} \mathrm{C}$ for $10 \mathrm{~min}$ was used to pole these crystals. A steady increase in the value of piezoelectric charge coefficients $\left(d_{33}\right)$ was observed as the poling field is increased. The $d_{33}$ value as high as $18 \mathrm{pC} / \mathrm{N}$ was achieved.

Figure 2 shows the electric polarization versus applied electric field curve (hysteresis or PE loop) for GP single crystal for different temperatures (from room temperature to $160{ }^{\circ} \mathrm{C}$ ) at $10 \mathrm{~Hz}$. For recording the PE loop, the maximum applied field was kept constant at $25 \mathrm{kV} / \mathrm{cm}$ and the temperature was varied in a controlled step rise of $3{ }^{\circ} \mathrm{C} / \mathrm{min}$. As evident form the curve, the width of the loop is found to decrease with temperature till $100{ }^{\circ} \mathrm{C}$. This shows the normal ferroelectric behavior of the sample in this temperature region. A straight line at $105^{\circ} \mathrm{C}$ was observed. At first instance, it seems to be the Curie point, beyond which the
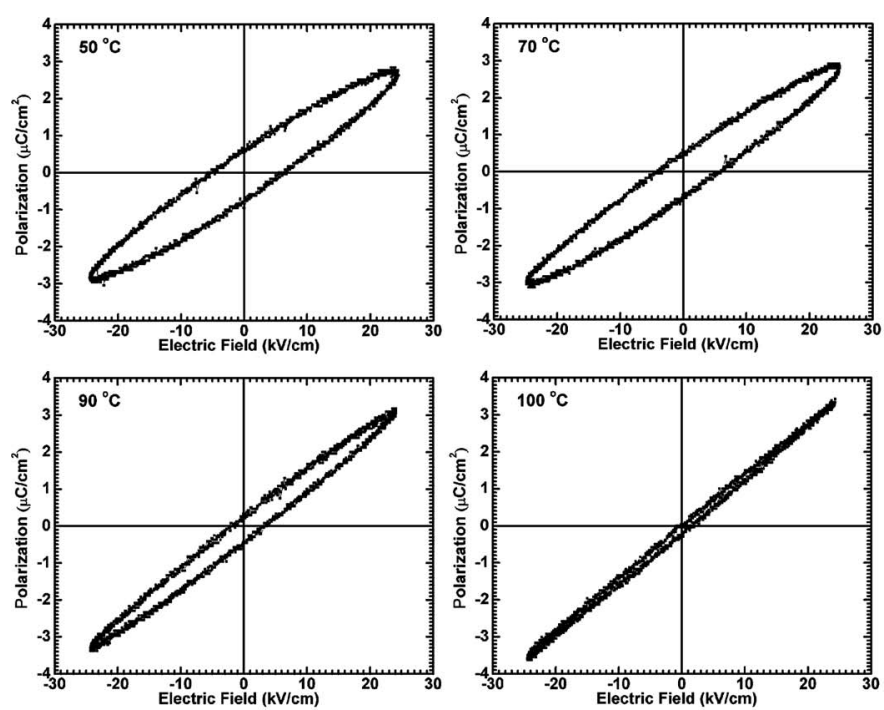
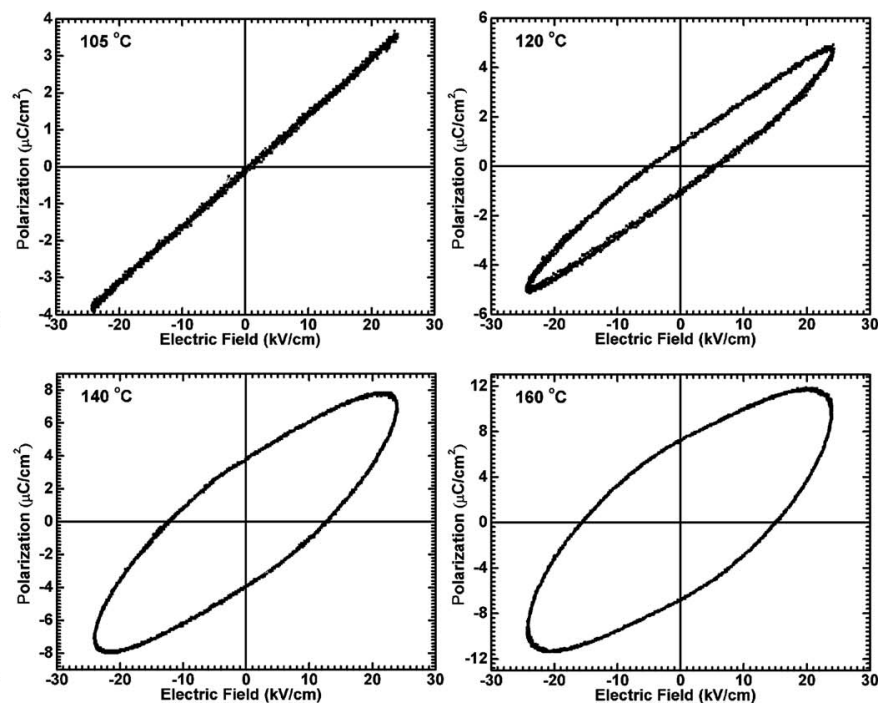

FIG. 2. Plot of hysteresis loop at various temperatures. 


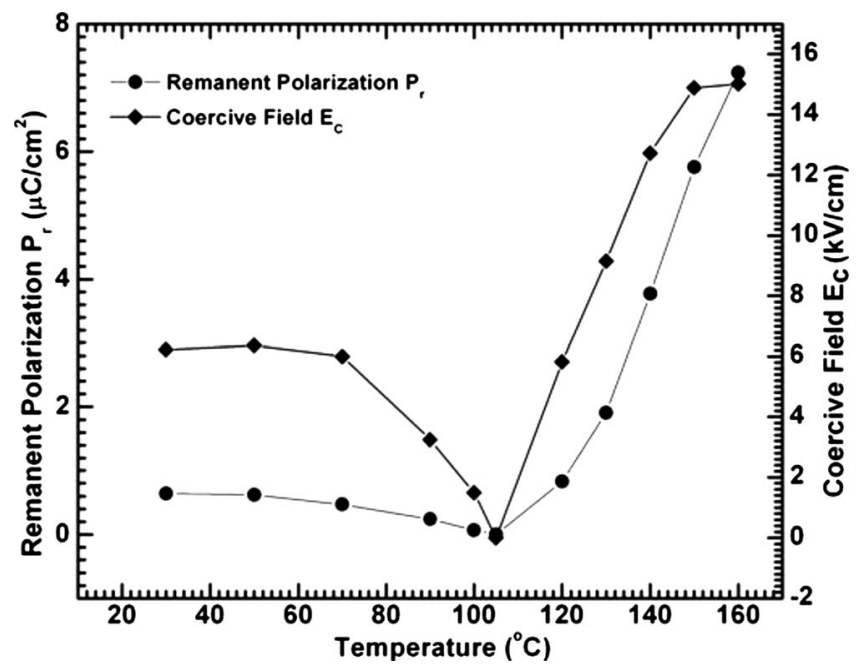

FIG. 3. Variation of remnant polarization and coercive field with temperature.

hysteresis loop is not expected due to the commonly expected transition from ferroelectric to paraelectric phase. But surprisingly, it is not the case. Beyond this temperature, an enhanced ferroelectric behavior was observed. Thus change in the switching behavior of the GP crystal at $105^{\circ} \mathrm{C}$ may be due to some ferroelectric to ferroelectric second order phase transition. The values of remnant polarization $\left(P_{\mathrm{r}}\right)$ and coercive field $\left(E_{\mathrm{c}}\right)$ were found to increase from 0.83 to $7.24 \mu \mathrm{C} / \mathrm{cm}^{2}$ and 5.82 to $15.02 \mathrm{kV} / \mathrm{cm}$, respectively in the temperature range from 120 to $160{ }^{\circ} \mathrm{C}$. The variation of $P_{\mathrm{r}}$ and $E_{\mathrm{c}}$ with temperature is shown in Fig. 3. Due to softening of the sample beyond $164{ }^{\circ} \mathrm{C}$, the hysteresis loops could not be traced.

The crystals were found to exhibit a fairly good switching behavior with remanent polarization as high as $7.24 \mu \mathrm{C} / \mathrm{cm}^{2}$. A ferroelectric to ferroelectric second order phase transition at $105^{\circ} \mathrm{C}$ was observed from dielectric, ac conductivity and PE loop analysis. A remarkable piezoelec- tric charge coefficient up to $18 \mathrm{pC} / \mathrm{N}$ was observed. The various results showed that GP is a promising candidate for various ferroelectric and piezoelectric applications. The combined NLO properties found recently and the ferroelectric, piezoelectric, and dielectric properties found in the present investigation revealed that the GP crystal is a promising organic crystal for photonic device applications.

The authors acknowledge Professor M. A. Wahab, Department of Physics, JMI for his continuous encouragement and useful discussions in pursuing the above studies. They also acknowledge Council of Scientific and Industrial Research, New Delhi and Department of Science and Technology, New Delhi.

${ }^{1}$ J. P. Farges, in Organic Conductors: Fundamentals and Applications (Marcel Dekker, New York, 1994), Chap. 8, pp. 311-358.

${ }^{2}$ T. Ishiguro and K. Yamaji, Organic Superconductors (Springer, Berlin, 1990).

${ }^{3}$ B. E. A. Saleh and M. C. Teich, Fundamental of Photonics (Wiley, New York, 1991).

${ }^{4}$ B. G. Penn, B. H. Cardelino, C. E. Moore, A. W. Shields, and D. O. Frazier, Prog. Cryst. Growth Charact. 22, 19 (1991).

${ }^{5}$ S. Yamaguchi, M. Goto, H. Takayanagi, and H. Ogura, Bull. Chem. Soc. Jpn. 61, 1026 (1988).

${ }^{6} \mathrm{H}$. Takayanagi, M. Goto, K. Takeda, and Y. Osa, Yakugaku Zasshi 124, 751 (2004).

${ }^{7}$ M. Briget Mary, V. Sasirekha, and V. Ramakrishnan, Spectrochim. Acta, Part A 65, 414 (2006).

${ }^{8}$ T. Kai, M. Goto, K. Furuhata, and H. Takayanagi, Anal. Sci. 10, 359 (1994).

${ }^{9}$ T. U. Devi, N. Lawrence, R. Ramesh Babu, and K. Ramamurthi, Spectrochim. Acta, Part A 71, 340 (2008).

${ }^{10}$ M. Shakir, S. K. Kushwaha, K. K. Maurya, M. Arora, and G. Bhagavannarayana, J. Cryst. Growth 311, 3871 (2009).

${ }^{11}$ K. E. Rieckhoff and W. L. Peticolas, Science 147, 610 (1965).

${ }^{12}$ T. Ishihara, K. Koshino, and H. Nakashima, Phys. Rev. Lett. 91, 253901 (2003).

${ }^{13}$ J. Dolinšek, D. Arcon, H. J. Kim, J. Seliger, V. Zagar, P. Vanek, J. Kroupa, Z. Zikmund, and J. Petzelt, Phys. Rev. B 57, R8063 (1998).

${ }^{14}$ O. Auciello, J. F. Scott, and R. Ramesh, Phys. Today 51, 22 (1998).

${ }^{15}$ A. Dekker, Solid State Physics (Prentice-Hall, Englewood Cliff, New Jersey, 1962). 